\title{
NGHIÊN CÚU ĐẶC ĐIỀM LÂM SÀNG, CẬN LÂM SÀNG VÀ MỘT SỐ YẾU TỐ LIÊN QUAN Ở BỆNH NHÂN ĐÁI THÁO ĐƯỜNG CÓ CẮT CỤT CHI DƯớI Nguyễn Thị Bích ${ }^{1}$, Nguyễn Quang Bảy ${ }^{2}$

\author{
${ }^{1}$ Bệnh viện đa khoa Nông Nghiệp, ${ }^{2}$ Trường Đại học Y Hà Nội
}

DOI: $10.47122 / v j d e .2020 .41 .10$

\begin{abstract}
Objective: The pressent study aims to review clinicals, subclinicals and related factors in diabetic patients withlower extremety amputation. Subjects and methods: This was a cross-sectional study of a sample of 75 diabetic patients with lower extremety amputation at the Department of Endocrinology, Bach Mai Hospital from January 2018 to August 2020. Results: Of the 75 patients studied, $65.3 \%$ was male, with mean age: $65,65 \pm 12,76$ years, mean duration of diabetes: 8,6 $\pm 0,9$ years... Most of the wounds were located on the toes, Wagner grade 4 or $5(97,3 \%)$, with severe infection; nevertheless, in about $54,7 \%$ of patients, osteomyelitis was suspected. Staphylococcus aureus was the most frequently isolated microorganisms. Those who required amputation presented high incidence of peripheral neuropathy $(64 \%)$, and peripheral artery disease (68.8- $70.1 \%$ of patients).The factors were found to be associated with lower extremety amputation were male, foot ulcer at Wagner grade 4 or 5,low albuminlevels, and high white blood cell counts. Conclusions: Diabetic patients with foot amputation usually are old, long duration of duabetes, and have PAD,peripheral neuropathy, severe infections with Wagner grade 4 or 5 . Other factors found in these patients are leukocytosis, low albumin levels, and poor glycemic control.
\end{abstract}

Keywords: lower extremity amputation, diabetes,peripheral artery disease.

\section{TÓM TÁT}

Mục tiêu: Nhận xét đặc điểm lâm sàng, cận lâm sàng và một số yếu tố liên quan ởbệnh nhân đái tháo đường có cắt cụt chi dưới. Đối tự̛ng và phương pháp nghiên cứu: Nghiên cứu mô tả cắt ngang trên các bệnh nhân đái tháo đường bị loét bàn chân có cắt cụt chi dưới điều trị tại Khoa Nội tiết Bệnh viện Bạch Mai từ tháng 01/2018 đến tháng 8/2020. Kết quả: Có tổng cộng 75 bệnh nhân trong nghiên cứu: $65,3 \%$ bệnh nhân là nam, tuổi trung bình $65,65 \pm 12,76$, thời gian mắc đái tháo đường trung bình là $8,6 \pm 0,9$ năm. Hầu hết các tổn thương bắt đầu từ ngón chân, loét độ Wagner 4 và Wagner 5(97,3\%), nhiễm trùng nặng (52,3\%). Ngoài ra, 64\% bệnh nhân có biến chứng thần kinh ngoại vi và $68,8-70,1 \%$ có bệnh động mạch ngoại vi. Staphylococcus aureus là vi khuẩn gặp nhiều nhất ở vết loét. Các yếu tố liên quan đến cắt cụt chi dưới gồm: nam giới, độ Wagner cao, giảm albumin máu, tăng bạch cầu. Kết luận: Bệnh nhân đái tháo đường có cắt cụt chi dưới đa số là nam, có các biến chứng về thần kinh ngoại vi và bệnh động mạch chi dưới kèm theo nhiễm trùng với độ Wagner cao(Wagner 4 hoặc 5), giảm albumin máu, tăng bạch cầu.

Tù khóa: cắt cut chi duới, đái tháo đường, bệnh động mach chi dưới, loét.

Chịu trách nhiệm chính: Nguyễn Thị Bích

Ngày nhận bài: 4/8/2020

Ngày phản biện khoa học: 5/9/2020

Ngày duyệt bài: 7/10/2020

Email: tudinhhuongtrang@gmail.com

\section{1. ĐẠTT VẤN ĐỀ}

Đái tháo đường là một yếu tố nguy cơ chính của cắt cụt chi dưới. Loét bàn chân liên quan đến ĐTĐ được coi là nguyên nhân chính của cắt cụt chi dưới không do chấn thương. Phần lớn tổn thương loét $(60-80 \%)$ sẽ lành, trong khi $10-15 \%$ trong số đó sẽ tái phát và tối đa $24 \%$ trong số đó cuối cùng sẽ dẫn đến cắt cụt chi. Loét chân do đái tháo đường và cắt cụt chi là một gánh nặng lớn cho các hệ thống 
chăm sóc sức khỏe ở cả các nước phát triển và đang phát triển. Tại các nước có nền kinh tế kém phát triển như Việt Nam, loét bàn chân và cắt cụt chi do đái tháo đường là nguyên nhân rất thường gặp.

Tuy nhiên, phần lớn các bệnh viện trên toàn quốc còn thiếu các trang thiết bị chẩn đoán, thiếu đội ngũ chuyên môn sâu điều trị tổn thương này. Xác định các yếu tố nguy cơ có liên quan tới tổn thương loét bàn chân và cắt cụt chi có vai trò quan trọng trong việc tiên lượng và dự phòng loét cho bệnh nhân có nguy cơ cao.

Vì vậy chúng tôi thực hiện đề tài với 2 mục tiêu: (1) Nhận xét đặc điểm lâm sàng, cận lâm sàng ở bệnh nhân đái tháo đường có cắt cụt chi dưới, và (2) Tìm hiểu một số yếu tố liên quan đến chi định cắt cụt chi.

\section{2. ĐỐI TƯợNG VÀ PHƯƠNG PHÁP NGHIÊN CÚU}

2.1. Đối tượng nghiên cứu

2.1.1. Tiêu chuẩn lựa chọn:

- Bệnh nhân được chẩn đoán ĐTĐ theo ADA 2019[1]

- Bệnh nhân có tổn thương loét bàn chân theo IWGDF 2019[2], phải cắt cụt chi dưới.

\subsubsection{Tiêu chuẩn loại trù̀:}

- Bệnh nhân không có đủ các số liệu cần cho nghiên cứu.

\subsection{Phương pháp nghiên cứu:}

Nghiên cứu mô tả cắt ngang, hồi cứu $(1 / 2018$ - 6/2019), và tiến cứu (7/20198/2020).

Đối tượng nghiên cứu được thăm khám và hỏi bệnh tiến hành theo mẫu bệnh án nghiên cứu thống nhất.

\subsubsection{Các biến số và chỉ số nghiên cứu:}

- Các biến số thông tin chung của bệnh về nhân như tuổi, giới , chiều cao, cân nặng, tiền sử mắc đái tháo đường, các biến chứng liên quan đến cắt cụt chi.

- Sử dụng bảng điểm michigan đánh giá biến chứng thần kinh ngoại vi. Chỉ số $\mathrm{ABI}$, siêu âm Doppler mạch chi dưới để đánh giá bệnh động mạch ngoại vi.

- Đánh giá nhiê̂m trùng theo IDSA 2012.

- Đánh giá độ sâu vết loét bằng phân độ Wagner. Xét nghiệm đường máu, HbAlc, mỡ máu, Creatin, Albumin, công thức máu.

- Cấy mủ vết loét.

- Các xét nghiệm được làm tại Bệnh viện Bạch Mai.

2.2.2. Xư lý số liệu: Các số liệu được phân tích và xử lý bằng phần mềm SPSS 20.0. Sự khác biệt có ý nghĩa thống kê khi p<0,05.

\section{KẾT QUẢ NGHIÊN CÚU}

\section{1. Đặc điểm chung của bệnh nhân nghiên cứu}

Bảng 3.1. Đặc điểm chung của đối tượng nghiên cứu

\begin{tabular}{|c|c|c|c|}
\hline \multicolumn{2}{|c|}{ Đặc điểm } & Số lượng(n=75) & Tỉ lệ (\%) \\
\hline \multirow{2}{*}{ Giới } & Nam & 49 & 65,3 \\
\cline { 2 - 4 } & Nũ & 26 & 34,7 \\
\hline \multirow{3}{*}{ Tuổi } & $<40$ & 2 & 2,7 \\
\cline { 2 - 4 } & $40-49$ & 3 & 4,0 \\
\cline { 2 - 4 } & $50-59$ & 21 & 28,0 \\
\cline { 2 - 4 } & $60-69$ & 16 & 44,0 \\
\cline { 2 - 4 } & $\geq 70$ & 33 & \multicolumn{2}{|c|}{$20,2 \pm 2,96$} \\
\hline \multicolumn{2}{|c|}{$8,6 \pm 0,9$} \\
\hline \multicolumn{2}{|r|}{ BMI(Trung bình \pm SD) } & \multicolumn{3}{|c|}{} \\
\hline
\end{tabular}

- Tuổi trung bình của các bệnh nhân là $65,7 \pm 12,8$ tuổi, nhóm tuối phố biến là $\geq 70$ tuổi.

- Các bệnh nhân có thời gian mắc đái tháo đường trung bình là $8,6 \pm 0,8$ năm. 


\subsection{Các bệnh đi kèm và biến chứng đái tháo đường}

Bảng 3.2. Các bệnh đi kèm và biến chứng đái tháo đường

\begin{tabular}{|l|l|c|c|}
\hline \multicolumn{2}{|c|}{ Đặc điểm } & Số lượng(n) & Tỉ lệ(\%) \\
\hline \multirow{3}{*}{ Tiền sử hút thuốc } & Chưa & 35 & 46,7 \\
\cline { 2 - 4 } & Đã dừng & 35 & 46,7 \\
\cline { 2 - 4 } & Còn & 5 & 6,7 \\
\hline \multirow{2}{*}{ Tiền sử cắt cụt } & Có & 10 & 13,3 \\
\cline { 2 - 4 } & Không & 65 & 86,7 \\
\hline \multirow{2}{*}{$\begin{array}{c}\text { Biến chứng thần kinh } \\
\text { ngoại vi }\end{array}$} & Có & 48 & 64 \\
\cline { 2 - 4 } & Không & 27 & 36 \\
\hline $\begin{array}{l}\text { Bệnh động mạch chi } \\
\text { dưới }\end{array}$ & Có & 21 & 61,8 \\
\cline { 2 - 4 } & Không & 13 & 38,2 \\
\hline
\end{tabular}

- Trên $50 \%$ bệnh nhân có hút thuốc lá, có biến chứng thần kinh ngoại vi, có bệnh động mạch chi dưới.

- Có $13,3 \%$ có tiền sử bị cắt cụt chi trước đó.

\subsection{Tổn thương chân}

Bảng 3.3. Tổn thương loét chân

\begin{tabular}{|c|c|c|c|}
\hline \multicolumn{2}{|c|}{ Đặc điểm } & Số lượng $(n=75)$ & Tỉ lệ ( \%) \\
\hline \multirow{3}{*}{ Mức độ nhiễm trùng } & Nhẹ & 8 & 10,7 \\
\hline & Vừa & 24 & 30,0 \\
\hline & Nặng & 43 & 52,3 \\
\hline \multirow{3}{*}{ Phân độ Wagner } & Độ 3 & 3 & 2,7 \\
\hline & Độ 4 & 39 & 52,0 \\
\hline & Độ 5 & 24 & 45,3 \\
\hline \multirow{2}{*}{ Viêm xương } & Có & 41 & 54,6 \\
\hline & Không & 34 & 45,4 \\
\hline
\end{tabular}

- $100 \%$ bệnh nhân cắt cụt chi dưới có nhiễm trùng kèm theo trong đó nhiễm trùng nặng theo IDSA 2012 chiếm 52,3\%. Có 54,6\% bệnh nhân có viêm xương kèm theo.

- Phân độ Wagner ở bệnh nhân cắt cụt chi dưới có 97,3\% là Wagner 4 và Wagner 5 .

3.4. Mức độ cắt cụt chi:

Có 41 bệnh nhân cắt cụt nhỏ (ngón chân, bàn chân) chiếm $54,7 \%$ và 34 bệnh nhân bị cắt cụt lớn (cắng chân,đùi), chiếm 45,3\%.

Bảng 3.4. So sánh đặc điểm chung ở 2 nhóm cắt cụt chi

\begin{tabular}{|c|c|c|c|c|c|c|}
\hline \multirow{2}{*}{\multicolumn{2}{|c|}{$\mathrm{P}_{\text {Đặc điểm }}^{\text {Nhóm }}$}} & \multicolumn{2}{|c|}{$\begin{array}{c}\text { Cắt cụt nhỏ } \\
(n=41)\end{array}$} & \multicolumn{2}{|c|}{$\begin{array}{c}\text { Cắt cụt lớn } \\
(\mathbf{n}=\mathbf{3 4})\end{array}$} & \multirow{2}{*}{$\mathbf{p}$} \\
\hline & & $\mathrm{n}$ & $\%$ & $\mathrm{n}$ & $\%$ & \\
\hline \multirow{2}{*}{ Giới } & $\mathrm{Nam}$ & 24 & $49,1 \%$ & 25 & $51,0 \%$ & \multirow{2}{*}{$>0,05$} \\
\hline & Nữ & 17 & $65,4 \%$ & 9 & $34,6 \%$ & \\
\hline \multirow{3}{*}{$\begin{array}{l}\text { Hút } \\
\text { thuốc lá }\end{array}$} & Chưa & 21 & $51,2 \%$ & 14 & $41,2 \%$ & \multirow{3}{*}{$>0,05$} \\
\hline & Đã dừng & 18 & $43,9 \%$ & 17 & $50,0 \%$ & \\
\hline & Còn & 2 & $4,9 \%$ & 3 & $8,8 \%$ & \\
\hline \multicolumn{2}{|c|}{ Tuối (Trung bình \pm SD) } & \multicolumn{2}{|c|}{$66,3 \pm 14,3$} & \multicolumn{2}{|c|}{$64,8 \pm 10,8$} & $>0,05$ \\
\hline \multicolumn{2}{|c|}{ BMI (Trung bình \pm SD) } & \multicolumn{2}{|c|}{$20,3 \pm 2,6$} & \multicolumn{2}{|c|}{$20,1 \pm 3,4$} & $>0,05$ \\
\hline
\end{tabular}




\begin{tabular}{l|c|c|c}
\hline Thời gian phát hiện & $8,76 \pm 6,99$ & $8,34 \pm 7,94$ & $>0,05$ \\
ĐTĐ (Trung bình \pm SD) & & & \\
\hline
\end{tabular}

Sự khác biệt về tuổi, giới, BMI, tiền sử hút thuốc và thời gian phát hiện đái tháo đường của 2 nhóm cắt cụt nhỏ và cắt cụt lớn không có ý nghĩa thống kê.

Bảng 3.5. Đặc điểm lâm sàng theomức độ cắt cụt chi

\begin{tabular}{|c|c|c|c|c|c|c|}
\hline \multirow{2}{*}{\multicolumn{2}{|c|}{$\underbrace{\text { Nhóm }}_{\text {Đặc điểm }}$}} & \multicolumn{2}{|c|}{$\begin{array}{c}\text { Cắt cụt nhỏ } \\
(n=41)\end{array}$} & \multicolumn{2}{|c|}{$\begin{array}{c}\text { Cắt cụt lớn } \\
(\mathbf{n}=\mathbf{3 4})\end{array}$} & \multirow[t]{2}{*}{$\mathbf{p}$} \\
\hline & & $\mathrm{n}$ & $\%$ & $\mathrm{n}$ & $\%$ & \\
\hline \multirow{3}{*}{$\begin{array}{l}\text { Mức độ } \\
\text { nhiễm } \\
\text { trùng }\end{array}$} & Nhẹ & 7 & $17,1 \%$ & 1 & $2,9 \%$ & \multirow{3}{*}{$<0,05$} \\
\hline & Vừa & 18 & $43,9 \%$ & 5 & $14,7 \%$ & \\
\hline & Nặng & 16 & $39,0 \%$ & 28 & $82,4 \%$ & \\
\hline \multirow{3}{*}{$\begin{array}{l}\text { Phân độ } \\
\text { Wagner }\end{array}$} & Độ 3 & 2 & $4,9 \%$ & 0 & $0,0 \%$ & \multirow{3}{*}{$<0,05$} \\
\hline & Độ 4 & 36 & $87,8 \%$ & 3 & $8,8 \%$ & \\
\hline & Độ 5 & 3 & $7,3 \%$ & 31 & $91,2 \%$ & \\
\hline \multicolumn{2}{|c|}{ Biến chứng TKNV } & 30 & $73,2 \%$ & 18 & $52,9 \%$ & $>0,05$ \\
\hline \multicolumn{2}{|c|}{$\begin{array}{l}\text { Bệnh động mạch chi } \\
\text { dưới }\end{array}$} & 26 & $63,4 \%$ & 23 & $67,6 \%$ & $>0,05$ \\
\hline \multicolumn{2}{|c|}{ Viêm xương } & 27 & $69,2 \%$ & 14 & $53,8 \%$ & $>0,05$ \\
\hline
\end{tabular}

- Sự khác biệt về tỉ lệ biến chứng thần kinh ngoại vi, bệnh động mạch chi dưới, viêm xương giữa 2 nhóm cắt cụt nhỏ và cắt cụt lớn không có ý nghĩa thống kê.

- Sự khác biệt giữa nhóm cắt cụt lớn và cắt cụt nhỏ giữa về mức độ nhiễm trùng và phân độ Wagner khác nhau có ý nghĩa thống kê $(\mathrm{p}<0,05)$.

Bảng 3.6. Đặc điểm cận lâm sàng và mức độ cắt cụt chi

\begin{tabular}{|c|c|c|c|c|c|}
\hline \multirow{2}{*}{ Đặc điểm } & \multicolumn{2}{|c|}{$\begin{array}{c}\text { Cắt cụt nhỏ } \\
(n=41)\end{array}$} & \multicolumn{2}{|c|}{$\begin{array}{c}\text { Cắt cụt lớn } \\
(\mathrm{n}=\mathbf{3 4})\end{array}$} & \multirow[t]{2}{*}{$\mathbf{p}$} \\
\hline & $\mathbf{n}$ & $\%$ & $\mathbf{n}$ & $\%$ & \\
\hline \multirow{2}{*}{ HbA1c } & 8 & $9,5 \%$ & 1 & $2.9 \%$ & \multirow{2}{*}{$<0.05$} \\
\hline & 33 & $80,5 \%$ & 33 & $97.1 \%$ & \\
\hline Mức lọc cầu thận & \multicolumn{2}{|c|}{$74,8 \pm 32,7$} & \multicolumn{2}{|c|}{$92,3 \pm \quad 57,7$} & $>0,05$ \\
\hline Cholesterol & \multicolumn{2}{|c|}{$3,44 \pm 1,08$} & \multicolumn{2}{|c|}{$3,17 \pm 1,15$} & $>0,05$ \\
\hline Triglyceride & \multicolumn{2}{|c|}{$1,34 \pm 0,62$} & \multicolumn{2}{|c|}{$1,83 \pm 1,02$} & $<0,05$ \\
\hline HDL- cho & \multicolumn{2}{|c|}{$0,88 \pm 0,35$} & \multicolumn{2}{|c|}{$0,62 \pm 0,3$} & $<0,05$ \\
\hline LDL- cho & \multicolumn{2}{|c|}{$1,94 \pm 0,83$} & \multicolumn{2}{|c|}{$1,71 \pm 0,82$} & $>0,05$ \\
\hline $\begin{array}{l}\text { Albumin máu } \\
\text { (Trung bình } \pm \text { SD) }\end{array}$ & \multicolumn{2}{|c|}{$28,71 \pm 4,55$} & \multicolumn{2}{|c|}{$22,78 \pm 5,85$} & $<0,05$ \\
\hline CRPhs(Trung bình \pm SD) & \multicolumn{2}{|c|}{$7,94 \pm 7,66$} & \multicolumn{2}{|c|}{$16,80 \pm 11,64$} & $<0,05$ \\
\hline $\begin{array}{l}\text { Bạch cầu } \\
\text { (Trung bình } \pm \text { SD) }\end{array}$ & \multicolumn{2}{|c|}{$11,84 \pm 4,36$} & \multicolumn{2}{|c|}{$20,33 \pm 10,28$} & $<0,05$ \\
\hline
\end{tabular}

HbA1c, nồng độ Triglycerid trung bình, HDL-C trung bình, albumin máu, CRPhs và số lượng bạch cầu giữa 2 nhóm khác biệt có ý nghĩa thông kê với $\mathrm{p}<0,05$.

\section{BÀN LUÂN}

Chúng tôi gặp bệnh nhân nam(65.3\%) nhiều hơn bệnh nhân $n$ ữ $(34,7 \%)$. Kết quả này tương tự với kết quả nghiên cứu của Lê Tuyết Hoa ghi nhận tî lệ cắt cụt chi ở nam cao hơn ở nữ $(61,5 \%$ so với $50 \%)[5]$. Các nghiên cứu 
khác trên thế giới cũng cho thấy tỉ lệ nam giới bị cắt cụt chi cao hơn so với nữ giới. Nghiên cứu của Moss cho thấy bệnh nhân đái tháo đường nam khởi phát trên 30 tuổi có nguy cơ bị loét chân gấp 1,6 lần và nguy cơ cắt cụt chi gấp 2,8 lần so với nữ[6]. Nhiều yếu tố có thể ảnh hưởng trên giới tính gây ra nam bị bệnh lí bàn chân nhiều hơn nữ. Các yếu này có thể bao gồm: mức hoạt động thể lực, thói quen hút thuốc lá, khác biệt về hormone, mức độ tuân thủ điều trị, trình độ giáo dục cũng như tỉ lệ và độ nặng của bệnh thần kinh, mạch máu và đái tháo đường.

Trong nghiên cứu của chúng tôi, tuổi trung bình của bệnh nhân là $65,6 \pm 12,8$ tuổi cũng tương tự với kết quả nghiên cứu nhiều tác giả trong và ngoài nước như Huỳnh Tấn Đạt 64,2 tuổi[7], nghiên cứu của N.M Yusof (2015) trên 218 bệnh nhân ĐTĐ ở Malaysia có cắt cụt chi vì loét chân cho thấy độ tuổi trung bình là 60,97[8]. Bên cạnh đó thời gian mắc bệnh ĐTĐ lâu, trung bình là $8,6 \pm 0,9$ năm so với nghiên cứu của Huỳnh Tấn Đạt là $8,3 \pm 6,7$ năm[7]).

Điều này cho thấy các bệnh nhân mắc đái tháo đường thường có tuổi đời khá cao và mắc bệnh trong thời gian dài nên thường có biến chứng mạn tính của tiểu đường như biến chứng thần kinh ngoại vi, bệnh động mạch ngoại biên... Cụ thể là $64 \%$ bệnh nhân có biến chứng thần kinh ngoại vi, $61,8 \%$ có bệnh động mạch chi dưới. Tương tự, trong nghiên cứu của Huỳnh Tấn Đạt, trên $60 \%$ bệnh nhân có biến chứng thần kinh ngoại vi[7], còn nghiên cứu của M.T Verrone Quilici thấy tỷ lệ bệnh nhân có biến chứng thần kinh ngoại vi là 91\%,bệnh động mạch chi dưới là 63\%[9].

Bên cạnh đó nhiễm trùng làm tăng nguy cơ cắt cụt chi ở bệnh nhân đái tháo đường có loét bàn chân. $100 \%$ bệnh nhân trong nghiên cứu của chúng tôi có nhiễm trùng từ nhẹ đến nặng,trong đó mức độ 3 và mức độ 4 của nhiê̂̀m trùng theo IDSA 2012 chiếm 82,3\% và theo phân độ Wagner 4 và Wagner 5 chiếm $97,3 \%$.

Nghiên cứu của Lavery sử dụng bảng phân loại nhiễm trùng chân của IWGDF/IDSA cho thấy nhiễm trùng nặng chỉ chiếm $17,9 \%$ còn lại là nhiễm trùng nhẹ $(47,0 \%)$ và trung bình (34\%)[10]. Như vậy nhiễm trùng chân mức độ nặng trong nghiên cứu của chúng tôi cao hơn rất nhiều so với dân số ở châu Âu và Mỹ. Sự khác biệt này có thể do khi có loét, các bệnh nhân ở Việt Nam thường tự điều trị tại nhà hoặc được điều trị bởi các bác sĩ không chuyên khoa cho đến khi nặng, đe dọa tính mạng mới đến được Bệnh viện Bạch Mai.

Đa số bệnh nhân có kiểm soát đường huyết kém đường huyết trung bình của bệnh nhân khi nhập viện là $14,31 \pm 6,97 \mathrm{mmol} / 1$ và HbA1C trung bình là $10,4 \pm 3,03 \%$ trong đó $88 \%$ số bệnh nhân có $\mathrm{HbAlc} \geq 7 \%$. Tương tự nghiên cứu của Huỳnh Tấn Đạt đường huyết trung bình lúc nhập viện là $245 \mathrm{mg} / \mathrm{dl}$ và HbAlc trung bình $10,4 \%$; chỉ có $5,9 \%$ bệnh nhân đạt mục tiêu điều trị theo khuyến cáo $<7 \%$ và $77,8 \%$ bệnh nhân có mức $\mathrm{HbA} 1 \mathrm{c}>$ $8 \%$.[7]. Kiểm soát đường huyết tồi sẽ làm khó kiểm soát nhiễm trùng, chậm liền vết loét... nên sẽ làm tăng nguy cơ bị cắt cụt chi.

5. KẾT LUẬN: Qua nghiên cứu 75 bệnh nhân đái tháo đường có cắt cụt chi dưới chúng tôi rút ra 2 kết luận sau:

1. Các bệnh nhân đái tháo đường bị cắt cụt chi dưới thường là nam giới, hút thuốc lá, mắc đái tháo đường lâu năm, kiểm soát đường huyết kém, có biến chứng về thần kinh ngoại vi, bệnh động mạch chi dưới và nhiễm trùng.

2. Các yếu tố liên quan đến cắt cụt chi là bạch cầu cao, albumin máu thấp, kiểm soát đường máu kém, rối loạn lipid máu, nhiễm trùng nặng.

\section{TÀI LIỆ THAM KHẢO}

1. American Diabetes Association (2019). Standards of Medical Care inDiabetes 2019. Diabetes Care 2019 Jan; 42(Supplement 1): S13-S28.

2. Apelqvist J, Bakker K, Van Houtum WH, et al (1999). International Consensus on the Diabetic Foot. The International Working Group on the Diabetic Foot. Amsterdam, The Netherlands, John Wiley \& Sons, 67. 
3. Fryberg RG (1998). Diabetic foot ulcers: current concepts. J Foot Ankle Surg 37, $440-446$.

4. Nguyễn Văn Chi, Trần Hậu Khang (2011). Bệnh lý bàn chân do ĐTÐ, Các thang điểm thiết yếu sử dụng trong thực hành lâm sàng, Nxb Y học, 378- 379

5. Lê Tuyết Hoa, Nguyễn Thy Khuê (2005), "Yếu tố nguy cơ đoạn chi trên bệnh nhân đái tháo đường loét bàn chân". Y học Thực hành, 507-508, tr. 742-750.

6. Moss S. E., Klein R., Klein B. E. (1992), "The prevalence and incidence oflower extremity amputation in a diabetic population". Arch Intern Med,152(3), pp. 610-6.

7. Huỳnh Tấn Đạt (2019) "Tỉ lệ đoạn chi và các yếu tố liên quan đoạn chi dưới ở bệnh nhân đái tháo đường có loét chân". Luận án Tiến sỹ y học- Trường $\mathrm{ĐH} \mathrm{Y}$ Dược Tp Hồ Chí Minh

8. Nazri Mohd Yusof, Ahmad Hafiz Zulkifly,

\begin{abstract}
Ahmad(2015)" Predictors of major lower extremety amputation among type II diabetic patients admitted for diabetic foot problems" Singapore Med J 2015; 56(11): 626-631
\end{abstract}

9. Maria Teresa Verrone Quilici, Fernando de Sá Del Fiol,Alexandre Eduardo Franzin Vieira, and Maria Inês Toledo(2016)" Risk Factors for Foot Amputation in Patients Hospitalized for Diabetic Foot Infection'J Diabetes Res. 2016;2016:8931508

10. Lavery L. A., Armstrong D. G., Peters E. J., Lipsky B. A. (2007), "Probetobone test for diagnosing diabetic foot osteomyelitis: reliable or relic?".Diabetes Care, 30 (2), pp. 270-4.

11. Ali F. AbuRahma et al. Noninvasive Vascular Diagnosis(2013)"University of South Florida duplex criteria for lower extremety arterial occlusive disease"-A Practical Guide to Therapy.3rd edition. Springer-Verlag London 2013. p.317. 